\title{
A sociologia de Florestan Fernandes
}

\author{
Maria Arminda do Nascimento Arruda
}

Se fosse possível apreender em uma única expressão os sentidos das mudanças em vigor no Brasil desde 1930, talvez pudéssemos classificá-los como inerentes a uma época de tradições fatigadas. Transformações de vulto aconteciam em todos os contextos da vida econômica, política, social e cultural, a suscitar outros estilos de se pensar o país, provocando o aparecimento de nova geração de intelectuais, os chamados "Intérpretes do Brasil" - Gilberto Freyre, Caio Prado Júnior, Sérgio Buarque de Holanda -, que enfrentaram, malgrado a diversidade que os caracteriza, o tema da construção da nossa modernidade nos termos da linguagem modernista ${ }^{1}$. Com eles, o modernismo deixa de ser o estilo avançado da literatura e das artes, chegando ao ensaio; o movimento das vanguardas, que na origem foi acentuadamente nacional, ofereceu condiçôes propícias à conformação das nossas peculiaridades; por fim, pôde-se construir uma imagem do país em chave positiva, o que não significou ipso facto perspectiva necessariamente otimista sobre o futuro da nação, mas que se singularizava ao rejeitar as visões baseadas na ideia de incompletude da nossa história, tendo como ponto de referência experiências forâneas. O ensaísmo crítico de corte modernista negou 1.Explorei em outro texto a relação entre os ensaios de 1930 e o modernismo (cf. Arruda, 2006). Para uma análise diferenciada sobre as relaçōes entre a obra de Gilberto Freyre e o modernismo, ver Araújo, 2005. a norma culta portuguesa como forma adequada de expressão intelectual, inscrevendo dicções incomuns no passado, ao mesmo tempo em que construiu retratos do Brasil que marcaram a cultura brasileira em toda a sua trajetória ulterior. Os ensaístas dos anos de 1930 lançaram as bases da reflexão 
2. "O nome próprio de quem assina o ensaio é um dos elementos-chave do gênero: ao assumir a primeira pessoa, o ensaísta assume também um compromisso explícito com o leitor, ao qual se propõe um pacto de leitura que, com seu nome próprio, assume a responsabilidade dos enunciados" (Saítta, 2004, p. 108). Ricardo Benzaquén analisa como Gilberto Freyre é personagem do seu próprio livro, apresentando-se "tanto como seu criador quanto como sua criatura" (Araújo, 1994, p. 199). moderna das ciências sociais brasileiras, legitimando o estilo de reflexão e de narrativa dessas disciplinas.

De fato, a experiência de constituição da sociologia moderna entre nós se pudermos identificá-la à formação acadêmica da disciplina - estava plasmada na intensa modernização do país, acentuada a partir do decênio de 1930 no trânsito da crise das relações sociais tradicionais, e vigorosamente inequívocas desde os anos imediatos ao término da Segunda Guerra Mundial, quando a riqueza nacional foi auferida, sobretudo, nas atividades industriais. A despeito do ritmo das mudanças, o ambiente ainda transpirava orientaçôes próprias à tradição, revelando o quanto se mesclavam presente e passado no Brasil daqueles anos. Todavia, o movimento da sociedade brasileira seguia sentido inverso ao da Europa, pois, enquanto lá ocorria perda da hegemonia civilizacional, aqui acontecia a débâcle do Estado Novo e a construção de instituições democráticas, acompanhadas da emergência de um surto desenvolvimentista sem paralelos até aquele momento. No plano cultural, a terceira década do século XX foi

[...] um eixo catalisador: um eixo em torno do qual girou de certo modo a cultura brasileira catalisando elementos dispersos para dispô-los numa configuração nova [...]. Em grande parte porque gerou um movimento de unificação cultural projetando na escala da nação fatos que antes ocorriam na escala das regiões (Candido, 2000, pp. 181-182).

Antonio Candido refere-se ao que denominou de "rotinização do modernismo", que se tornou o estilo dominante de expressão das elites intelectuais e artísticas brasileiras. O ensaio sociológico de 1930 situa-se entre a cultura tradicional, na medida em que representa uma modalidade de vida intelectual fortemente ancorada numa narrativa na qual o autor fala em nome próprio, e a vida intelectual desenvolvida em quadros institucionais ${ }^{2}$. Por fim, os ensaístas estavam na origem das ciências sociais entendidas numa acepção abrangente (cf. Araújo, 2005, p. 17) ao elegerem como problema central das suas reflexões os dilemas e as potencialidades do país para construir a sociedade moderna em terras tropicais de origem portuguesa. Este problema ganhou, especificamente, significado naqueles anos de franco reconhecimento do atraso de Portugal e de reordenamento das hegemonias mundiais.

Foi no bojo de tais transformações que se criou a Universidade de São Paulo, em 1934, e, com ela, a Faculdade de Filosofia, Ciências e Letras que abri- 
gou o curso de ciências sociais. A USP emergiu, desse modo, das novas concepçôes que passaram a orientar os mentores das instituições culturais que propugnavam por organismos coincidentes com o clima reinante, embora não encarnassem completamente os valores negadores da tradição, pois a instituição foi fruto do consórcio entre iniciativas avançadas no plano educacional e os projetos políticos das elites ilustradas oriundas do passado (cf. Cardoso, 1982). Esses aparatos institucionais modernos que vinham sendo construídos desde a terceira década cresceram e se diversificaram na fase seguinte com a criação de variadas fundações culturais (cf. Arruda, 2001). A Universidade permitiu a formação sistemática de cientistas devotados à docência e à pesquisa, além de engendrar uma concepção diversa do conhecimento, pois construiu novos espaços de atuação para os praticantes das várias disciplinas que compunham o quadro das carreiras científicas inauguradas, especialmente, na Faculdade de Filosofia da USP. A introdução de procedimentos sistemáticos ao treinamento de profissionais foi êmulo fundamental à institucionalização do saber característico das ciências sociais, que fazia parte do cenário diferenciado de realização das vocações científicas e compartilhava do clima característico da sociabilidade acadêmica.

Nesse cenário de fundas transformações e de apostas modernizadoras, berço da moderna sociologia brasileira, Florestan Fernandes (1920-1995) destacou-se como a personalidade mais singular em meio aos primeiros cientistas sociais egressos da universidade ${ }^{3}$. Nenhum dos seus contemporâneos identificou-se, como ele, com a missão de edificar as bases científicas da sociologia no Brasil; tampouco a nenhum da sua geração pôde-se atribuir papel de tal proeminência no campo da teoria, da pesquisa sociológica, da atuação institucional e do entendimento da dimensão profissional do métier. Por essa razão, a imagem do sociólogo brasileiro, hoje difundida, inspirou-se largamente na sua trajetória pessoal e institucional, estilo que vinha se desenvolvendo desde, pelo menos, o meio século XX, como decorrência da fundação da Universidade de São Paulo e do modelo de pesquisa introduzido pela Escola Livre de Sociologia e Política de São Paulo, criada em 1933, combinados à tradição brasileira do intelectual público, especialmente marcante no Rio de Janeiro. O perfil do cientista social compôs-se, portanto, no encontro entre essas diversas tradições, que pressupôs o ensino sistemático das disciplinas em moldes científicos e o envolvimento com as questões públicas do país. A junção de tais atributos convidava às investigações sistemáticas sobre os caminhos da mudança em marcha, ao mesmo tempo em que era tributária das apostas que envolviam os dias presentes.
3. Para uma análise diferenciada da biografia e formação intelectual de Floresta Fernandes, ver Garcia, 2002. Para o tratamento do caráter moderno e pioneiro da sociologia de Florestan Fernandes, ver Arruda e Garcia, 2003. 
4.Frase cunhada por Fernandes (1965, p. 394).
De fato, na vivência dos contemporâneos, o Brasil inaugurava uma época alvissareira e plena de promessas, descortinando-se a efetiva capacidade de "forjar nos trópicos esse suporte de civilização moderna" ${ }^{4}$. Tratava-se, em suma, de um tempo com alto grau de dinamismo, no qual a crença nas possibilidades infinitas do desenvolvimento cultural era homóloga à convicção da modernização econômica, política e social da nação e que tinha na industrialização e na urbanização aceleradas o polo dinâmico. Assim, o presente aspirava ao futuro civilizado que, diga-se de passagem, seduzia o conjunto dos brasileiros aptos a perceber as transformações em curso. Produziu-se, sobretudo em São Paulo, o epicentro das energias mais vitais, a confluência do poder econômico e político com o "mundo do espírito". Entre dinheiro e intelecto ocorreram certas analogias no plano formal, como revelara Simmel, caracterizadas pelo impulso permanente de atualização:

Ao lado da objetividade impessoal inerente ao conteúdo da inteligência existe uma relação tremendamente próxima entre inteligência e individualidade [...]. O duplo caminho no qual tanto o intelectual como o dinheiro se tornam inteligíveis é a distinção do seu conteúdo objetivo essencial de sua função, ou, em outras palavras, nos usos em que são postos (1997. p. 437).

Numa quadra de crescente diferenciação da cultura e de democratização do acesso à vida cultural, combinadas ao dinamismo econômico e à mobilidade social intensa, isto é, ao caráter objetivo e subjetivo do dinheiro, as condições indispensáveis à equalização formal das duas esferas estavam dadas.

Juntamente a essas mudanças, deve-se acrescentar o processo de constituição das instituições democráticas e de criação de organismos para financiar a política desenvolvimentista do Estado brasileiro, no período de 1946 a 1964. Francamente modernizadores, os governos implementavam medidas de superação do atraso, com a consequente ultrapassagem das formas tradicionais herdadas do passado. A sociologia no Brasil bebeu na fonte da modernização em curso e elegeu como problema fundamental da reflexão a formação da sociedade moderna no país: suas possibilidades, tensões, impasses e dilemas no desenrolar das transformações. O tema da mudança social foi, assim, a questão central a mobilizar os intelectuais. Se o envolvimento com o moderno não era novo, pois ocupou corações e mentes dos letrados brasileiros pelo menos desde a Independência, a novidade residia no modo como se passou a refletir sobre o assunto: as concepções de conhecimento científico, construídas a partir de pesquisas rigorosas, modularam 
o tom do debate. Novamente aqui, o novo cenário conferiu os fundamentos sociais do pensamento científico, uma vez que o conhecimento abstrato é típico de contextos democráticos.

O que leva à abstração e à análise não provém das coisas em si mesmas. Sua origem é social: é ocasionada pelo tamanho e pela estrutura do grupo no qual o conhecimento tem que ser participado [...]. Podemos concluir que uma sociedade democrática é mais adequada para descobrir as correlações abstratas entre as coisas do que uma sociedade aristocrática (Mannheim, 1963. p. 265).

As concepções sociológicas de Florestan hauriram da sociologia mannheimiana parte essencial das suas motivações, evidenciadas no significado que atribuiu ao papel dos intelectuais na vida das sociedades, presentes nas suas formulações sobre a "civilização científica", resultaram também das análises sobre os dilemas da modernização no Brasil. A consciência de que a nossa formação moderna era particular não o impediu, especialmente ao longo dos anos de 1950, de admitir a real possibilidade de se criar no país princípios de uma modernidade ancorada em valores democráticos. Nos seus termos, apesar de a "transplantação da civilização ocidental para a zona tropical" constituir-se "em processo penoso, cheio de dificuldades e de transtornos", era viável a construção da civilização moderna no país, caso certos requisitos como o da expansão da educação e o da intervenção racional das ciências sociais fossem realizados (Fernandes, 1974. p. 311 - as referências seguintes a essa obra seguirão a segunda edição). Nos dois campos, Florestan atuou ativamente, articulando sua capacidade de ação em prol da democratização do acesso ao ensino em todos os níveis, exprimindo o compromisso selado com sua origem popular. Ele próprio havia sido fruto das oportunidades ampliadas no campo educacional e da criação da Universidade de São Paulo, para cujo concurso os renovadores da educação foram decisivos, como o foi Fernando de Azevedo, que o convidou para ser seu assistente em 1944.

Sua aposta no processo de constituição, no Brasil, dos princípios civilizados da sociedade moderna apresentou, todavia, variações ao longo de sua trajetória acadêmica, que compreendeu os anos de 1945 a 1969, datas da sua admissão como professor da USP e do seu afastamento compulsório em função do arbítrio do regime militar, instalado em 1964. Interessante perceber a mudança ocorrida ao longo desses anos, a partir de um trabalho modesto e circunscrito, no qual o sociólogo analisa a condição do marginal. 
5. A primeira edição do trabalho está na Revista do Arquivo Municipal, São Paulo, vol. LVII, 1946; a segunda, em Mudanças sociais no Brasil, São Paulo, Difusão Europeia do Livro, 1960; a terceira é a edição utilizada aqui.

6. Martins (1996) analisa os estudos biográficos de Florestan. Além do texto sobre Tiago Marques, Martins refere-se à pesquisa, realizada por Florestan em Sorocaba, sobre João de Camargo, líder carismático, e o conjunto de textos reunidos em $A$ contestação necessária: retratos intelectuais de inconformistas e revolucionários (1995). Este últimolivro, no entanto, resultou de escritos que conformam perfis de amigos, companheiros de partido ou de intelectuais brasileiros e latinoamericanos que expressaram posiçōes radicais. É uma obra que se enquadra no campo dahistória intelectual.

7. José de Souza Martins (1998) analisa o conjunto de trabalhos de Florestan Fernandes sobre trajetórias biográficas.
Em 1945, Florestan Fernandes, sociólogo recém-formado, apresenta o trabalho "Tiago Marques Aibopureu: um bororo marginal”, no Seminário sobre os Índios do Brasil, organizado por Herbert Baldus (Fernandes, 1975). Florestan utiliza-se do material recolhido por Herbert Baldus, Antônio Colbacchini e César Albisetti (cf. Idem, p. 85). O artigo foi republicado pelo menos mais duas vezes, em 1960 e 1975, sem alteraçôes, mantendo-se a forma original ${ }^{5}$. A escolha do assunto já era per se atraente; mais instigante ainda foi o tratamento conferido à biografia do índio Bororo. Chamam a atenção também as datas das publicações: a primeira, quando o jovem cientista social foi admitido na vida universitária; a segunda, quando se tornara um acadêmico prestigiado, incontestavelmente reconhecido em função dos trabalhos já produzidos que lhe carrearam posição institucional de relevo; a última, quando estava afastado da academia. As três situaçóes correspondiam, então, a momentos singulares da trajetória de Florestan. Nos extremos coincidiam fases de rupturas e de reconstituição da sua vida, vincadas pela metamorfose do menino pobre em professor da Universidade de São Paulo, e do sociólogo reconhecido que perdera o espaço privilegiado, lugar de excelência onde depositara as apostas profissionais e afetivas de sua existência. Este trabalho de pretensões modestas elege-se como referência à produção ulterior de Florestan, destacando-se em meio ao conjunto de escritos iniciais do sociólogo, por ater-se a reflexôes sobre um caso singular ${ }^{6}$. Por outro lado, o estudo situa-se em ponto intermediário, mediando as análises sobre folclore e cultura popular, seguidas pelos chamados estudos etnológicos ${ }^{7}$.

A análise da história de Tiago Marques Aibopureu foi construída de modo a que o singular e o geral se autoesclarecessem, pondo em relação abordagens micro e macrossociológicas, chegando, no limite, ao registro da psicologia social. O texto voltava-se, em suma, para o tratamento do conflito entre o indivíduo e a sociedade; para a conformação de personalidades tensionadas por situações que não se elucidavam no plano das escolhas individuais; para a expressão do movimento de negação da herança e a impossibilidade de completá-lo.

Os caminhos tortuosos de Tiago guardavam semelhanças com o percurso do autor, mas se distinguiam no essencial. Florestan Fernandes, situado entre dois mundos - o das classes populares e o da Universidade -, diferentemente do Índio Bororo, construiu uma "solução ativa" que lhe permitiu romper o estranhamento inicial, gestado na natural dificuldade de uma pessoa socialmente desenraizada conviver com um ambiente bas- 
tante elitizado da Faculdade de Filosofia, nos seus primeiros tempos ${ }^{8}$. Florestan rompeu o "círculo de ferro" da sua origem social à custa de muito empenho, dedicação, trabalho e absoluto controle dos seus atos. Fez da Universidade o espaço único de sua autoconstrução, abraçando-o com a força da urgência de quem não podia fraquejar diante das circunstâncias adversas:

Falando de Florestan Fernandes, é preciso assinalar que, além da obra de sociólogo e da ação de intelectual empenhado nos problemas do tempo, além da atividade de professor, de formador de equipe, de criador de rumos na teoria e na investigação, ele realizou outra obra não menos admirável: a construção de si mesmo (Candido, 1996. p. 63).

A trajetória de Florestan Fernandes, como de resto de muitos intelectuais latino-americanos, foi exemplar no sentido de reproduzir os caminhos e os descaminhos da história brasileira, rumo à construção da moderna sociedade capitalista no país. Tal como vários outros cientistas sociais do continente, a exemplo de Gino Germani, na Argentina, cuja obra encarnou "os dilemas e as interrogações enfrentadas por sua época" (Blanco, 2006. p. 19), a reflexão de Florestan - como a de todo intelectual de envergadura - impregnou-se dos problemas essenciais que se vão apresentando no decurso da sua vida, mas teve nos anos de 1950 um momento privilegiado, exatamente o período que abrigou as mais diversificadas promessas. Aqueles anos nos quais o Brasil perseguiu "um ideal de moderno marcado pelo progresso, auto-aperfeiçoamento e aperfeiçoamento ilimitado do social, e pela reorientação de valores, interesses, condutas e instituiçôes" (Botelho, 2008, p. 15). Esta foi a década da construção da sociologia de Florestan Fernandes e da organização da chamada Escola Paulista de Sociologia que congregou seus assistentes, cujos trabalhos afirmaram um estilo próprio de produção das ciências sociais no país (cf. Arruda, 2001). Foi um período em que uma intelectualidade de novo corte, posto que especializada, mobilizou suas ideias no sentido de construir projetos de Brasil, numa tentativa de regenerar a nação de um passado que se condenava (cf. Bastos, 2008, pp. 27-64). Foram anos, enfim, em que se acreditou no poder das ideias e na força da intelectualidade em produzir as mudanças tão esperadas (cf. Villas Boas, 2006); foi uma quadra de crença no poder transformador das ideias e do uso social do conhecimento9 ${ }^{9}$ Nesse meio século, o ritmo do desenvolvimento no Brasil superou todos os índices mundiais, combinado a uma realidade
8. "Eu seria, como figura humana, aquilo que os historiadores, os antropólogos e os sociólogos chamam de personalidade desenraizada. Eu sou um desenraizado" (Fernandes, 1978, p. 30).

9. Sobre o projeto de intervenção da sociologia de Florestan, ver Arruda e Garcia, 2003, especialmente Parte 2. 
política de franca distensão e aberta à participação e ao dissenso. A sociologia brasileira floresceu nesse solo de promessas franqueadas.

A Escola Paulista de Sociologia, no entanto, buscou demarcar, com muita nitidez, as diferenças entre a atuação pública do cientista social do seu compromisso com o conhecimento rigoroso, seguindo a orientação de Florestan, que não se alforriava da ciência e para qual dirigia a maior parte de suas energias, projeto, aliás, comum a outros cientistas sociais da América Latina que tiveram papel central na renovação das disciplinas, delineando seus rumos vindouros, como foi o caso de Gino Germani, na Argentina peronista (cf. Neiburg, 1997, pp. 157-184). Por todos os motivos assinalados, esses cientistas sociais tiveram que moldar os novos papéis, modelar a nova figura, em um espaço aberto a estilizações. Não por casualidade, Florestan e Germani eram representantes típicos da condição outsider: o primeiro por ser originário dos estratos inferiores das camadas populares; o segundo em função da sua condição de recém-emigrado que "não era individualmente conhecido [...] nem estava conectado com algum movimento intelectual visível” (Blanco, 2006, p. 244). A compreensão do potencial de inovação requeria, portanto, o tratamento das disposiçōes diversas aos sujeitos imersos no processo, bem como a maneira como aderiam ao novo estilo e identificavam-se com as instituições.

A universidade abriu, para Florestan, oportunidades materiais e simbólicas essenciais a uma pessoa despossuída de bens de raiz, conforme explicitou em entrevista publicada em 1975: "Eu nunca poderia ter me tornado sociólogo se eu não fosse professor de sociologia da USP” (Entrevista de Florestan Fernandes, 1975, p. 39). Antonio Candido, companheiro de rota, assim se expressou sobre o papel do sociólogo: "Ele revolucionou a situação [...] foi ele quem consolidou o espírito e a organização científica, como condição sine qua para a qualificação de um sociólogo" ("Prefácio", 1978). Suas preocupaçôes com a afirmação da sociologia como disciplina científica requeriam definir com rigor e clareza os métodos adequados a sustentar as pesquisas.

A magnitude do empreendimento é vislumbrada, nitidamente, pelo sociólogo paulista: "Não nos devemos esquecer que estávamos na década de 40 e 50 e que, então, o fundamental era construir a Sociologia como uma ciência empírica” (Entrevista de Florestan Fernandes, 1975, p. 12). Daí a absorção de contribuições teórico-metodológicas diversas e o impulso de sorver, em diferentes fontes, a inspiração necessária; Florestan não possuía preconceitos teóricos: "Não devemos exorcizar nem a pala- 
vra função, nem a análise causal resultantes de elaborações interpretativas estruturais-funcionais. Elas são instrumentais. O que se deve exorcizar é uma concepção naturalista de Ciências Sociais: esse é que é o busílis da questão" (Idem, p. 56). Ou ainda: "Não se tratava de ver Marx em termos dos dogmatismos de uma escola política. Marx emergia diretamente de seus textos e do seu impacto teórico na Sociologia” (Idem, p. 14). Ou, em outros termos, o fundamental é trabalhar no plano das construções teóricas, distinguindo os princípios da análise dos seus desdobramentos políticos. Mesmo no final da década, quando Florestan paulatinamente começou a rever certas posições, manifestou cautela à adesão, não mediada, do conhecimento aos problemas sociais:

[...] é inegável que os influxos do meio ambiente na formação do sociólogo brasileiro são, sob diversos aspectos, altamente construtivos. Em particular, eles favorecem a criação de uma atitude mais aberta e renovadora, seja em face das possibilidades de síntese teórica na Sociologia, seja diante da contribuição que as Ciências Sociais podem dar no terreno da aplicação. Todavia, elas tendem a corromper o equilíbrio que precisa existir, no mundo da ciência, entre móveis positivos e os móveis extras científicos das investigaçōes (Fernandes, 1958, p. 213).

O projeto científico construído por Florestan pressupunha, como se viu, uma agenda de pesquisa derivada das concepções de rigor do conhecimento, cuja aplicação seria intrínseca à própria natureza da ciência. Os especialistas teriam condiçôes de mobilizar os resultados das pesquisas para alterar sistemas de relaçôes, por meio de novas descobertas forjadas no embate com as questões sociais. No campo da sociologia, o especialista seria a figura do profissional da corporação científica, um observador dos fenômenos sociais, capaz de formular regras de explicação e de propor medidas de correção. O problema fundamental da sociologia no Brasil residia, de acordo com as suas concepções, na necessidade de refinar os métodos intrínsecos ao caráter aplicado da ciência de modo a readequá-los ao tratamento de sociedades mais heterogêneas e menos orgânicas, como a brasileira. Sua rejeição às formas aderentes do saber, ao movimento social dominante, não significava, pois, desaprovação às iniciativas de intervenção. Contrariamente, nutria grande apreço pelas contribuições da Escola Sociológica de Chicago: "Dadas as analogias entre Chicago e São Paulo e os nossos propósitos de expandir aqui a investigação sociológica, a tentativa de converter São Paulo em um laboratório (ou em um campo especial de trabalho concen- 
10. "São várias as ressonâncias da Escola de Chicago no Departamento de Ciências Sociais da USP de agenda reformadora e que quer conduzir o seu investigador a uma imersão na vida local” (Vianna, 1997, p. 190). Refiro-me ao seu mestrado (s/d.) e ao doutorado (1970). Este livro é considerado uma obra-prima da antropologia social. trado dos sociólogos) atraía o melhor da minha imaginação" (Fernandes, 1980, p. 170). A instituição universitária moderna seria o locus de legitimação do desenvolvimento de propostas de intervenção social, o foro privilegiado de padrões de trabalho necessários à construção da sociologia científica no país. A compreensão da sociologia, segundo tal registro, dirigiu os interesses de pesquisa de Florestan Fernandes, que combinou trabalhos eminentemente de teoria e métodos - mesmo as suas teses no campo da etnologia foram, em substância, alentados exercícios teóricos ${ }^{10}-$ a outros voltados ao tratamento da civilização industrial e da formação da sociedade de classes, isto é, da moderna sociedade burguesa em um contexto permeado por orientaçôes valorativas oriundas do passado escravista.

A integração do negro na sociedade de classes, tese apresentada para o concurso de Cátedra em Sociologia, em março de 1964, cargo que ocupava de fato desde 1954 no exercício do papel de regente de Sociologia I, em função do retorno de Roger Bastide à França, representou uma mudança de inclinação na perspectiva analítica de Florestan. Monografia exemplar, a tese retomava suas preocupações sobre o tema das relações raciais e do preconceito racial, iniciadas com a pesquisa promovida pela Unesco em diferentes regiões do Brasil, entre os anos de 1949 e 1951, e que foi elaborada em parceria com Roger Bastide. A obra revelou o amadurecimento da reflexão do sociólogo sobre o processo de constituição do Brasil moderno, evidente na posição de franco recuo em relação à sua aposta sobre as possibilidades efetivas de se construir no Brasil os princípios civilizatórios modernos. Situando a problemática do negro na passagem da sociedade escravista para a sociedade de classes, o sociólogo analisou as relações raciais pelo prisma da dinâmica global da modernização brasileira, acentuada na cidade de São Paulo. A rápida transformação urbana, ocorrida entre o final do século XIX e o começo do século XX, impossibilitou a inserção do negro e do mulato no estilo urbano de vida, por não possuir recursos para enfrentar a concorrência dos imigrantes. Ou, para acompanhar as suas categorias, a heteronomia presente na "situação de castas" impediu aos negros assimilar as potencialidades oferecidas pela "situação de classes". Resulta desse processo, o "desajustamento estrutural", a "desorganização social”, típicas da condição dos descendentes de africanos, relegados a viver um estado de marginalidade social, verdadeiros proscritos das conquistas civilizadas. O preconceito e outras expressões de discriminação exerceram a função "de manter a distância social" e de reproduzir o "isolamento sociocultural", tendo em vista a preservação das "estruturas sociais arcaicas”. O ritmo intenso da história em São Paulo produziu 
forte descompasso entre a ordem social (mais sincronizada com as transformaçôes da estrutura econômica) e a ordem racial (de ajustamento mais lento às mudanças), permanecendo como uma espécie de "resíduo do antigo regime", cuja eliminação futura adviria dos "efeitos indiretos da normalização progressiva do estilo democrático de vida e da ordem social correspondente".

Explicita-se, nessas passagens, o entendimento da particular realização da sociedade moderna no Brasil, como processo complexo e de resultados híbridos, uma vez que, a despeito do ritmo das transformações, padece de uma sorte de fraqueza congênita, comprometendo todo o seu desenvolvimento ulterior. As análises sobre a herança da escravidão inseriam-se, dessa maneira, na busca de compreender como os fundamentos da sociedade brasileira produziam bloqueios à plena consecução de princípios civilizados, verdadeiros anteparos à pura modernidade capitalista. $\mathrm{O}$ projeto de investigar o papel das relações escravistas no Brasil na constituição da sociedade nacional desdobrou-se nos trabalhos escritos por seus assistentes, como Fernando Henrique Cardoso, Octávio Ianni, Maria Sylvia de Carvalho Franco, entre outros colaboradores. A articulação dos temas de pesquisa deu frutos e produziu afinidades intelectuais ao grupo reunido por Florestan, justificando a identificação posteriormente construída e sintetizada na expressão Escola Paulista de Sociologia, apesar de a convivência não ter sido sempre apaziguada e comportar diferenças internas entre os participantes.

O sentimento de evidente ceticismo a percorrer as páginas de $A$ integração do negro na sociedade de classes marcava o fim das reflexóes sistemáticas do sociólogo sobre o tema, lançando-se em novo projeto: Economia e sociedade no Brasil: análise sociológica do subdesenvolvimento seguido do plano de estudos "A empresa industrial em São Paulo", concebidos por ele e Fernando Henrique Cardoso com a finalidade de nortear as pesquisas que seriam desenvolvidas no Centro de Sociologia Industrial e do Trabalho (Cesit), criado em 1962, por intermédio de financiamento público e privado. Durante os nove anos de existência do Cesit, trabalhos de relevo foram produzidos a partir das pesquisas implementadas e dos amplos levantamentos que visavam conhecer de modo sistemático e rigoroso os rumos da modernização brasileira e da particularidade da "civilização industrial no Brasil". A criação do Cesit representou a entrada definitiva dos sociólogos paulistas no debate sobre o desenvolvimento do país, incorporando-se ao coro dos cientistas sociais vocalizadores de projetos voltados ao desenvolvimento nacional, como ocorria no meio dos cientistas sociais do Instituto Superior 
de Estudos Brasileiros (Iseb), sediado no Rio de Janeiro e patrocinado pelo Estado. A criação do centro paulista, abrigado na USP, ao lado da proverbial vitalidade do Iseb e da experiência inovadora ensaiada pelo Curso de Sociologia e Política, da Faculdade de Ciências Econômicas da Universidade de Minas Gerais, demonstrava o vigor e a relevância adquiridos pelas ciências sociais no Brasil ao longo dos anos que se seguiram aos acontecimentos traumáticos do pós-guerra. Havia um clima de franca aposta no desenvolvimento dos países latino-americanos, no qual a Cepal era exemplo contundente. Com $A$ integração do negro na sociedade de classes, o sociólogo ressalta a presença de impasses inerentes a um processo de modernização sem vigor para superar o legado do passado; a fraqueza do moderno acabou por bafejar a tradição com um sopro de vida, quando a ela se combinou. Com o livro A revolução burguesa no Brasil: ensaio de interpretação sociológica, essas concepçōes conferiram urdidura à obra, levando-o a desenvolver categorias adequadas ao tratamento dos problemas e entraves típicos de sociedades que não realizam as formas avançadas da civilidade moderna.

O livro A revolução burguesa no Brasil é fundamental para explicitar o percurso do sociólogo (Fernandes, 1975). Obra de grande vulto, voltada à análise do processo histórico de formação da sociedade burguesa no Brasil, desde a Independência até os desdobramentos do golpe militar de 1964. Este texto, repleto de nuanças, expõe nítida clivagem no âmbito do pensamento do autor e que se manifesta no próprio corpo da análise. Escrito entre 1966 e 1974, sofreu uma interrupção no seu processo de feitura de cerca de três anos, período no qual Florestan lecionou na Universidade de Toronto. $\mathrm{O}$ autor, de saída, explicou o modo como percebe o seu empreendimento:

É preciso que o leitor entenda que não projetava fazer obra de "Sociologia acadêmica”. Ao contrário, pretendia, na linguagem mais simples possível, resumir as principais linhas da evolução do capitalismo e da sociedade de classes no Brasil. Trata-se de um ensaio livre, que não poderia escrever se não fosse sociólogo. Mas que põe em primeiro plano as frustrações e as esperanças de um socialista militante (Idem, pp. 9-10).

Apesar das intenções declaradas do autor, o livro é um exercício acadêmico de interpretação, no qual as peculiaridades desse estilo se encontram sobejamente presentes. Perquirindo o significado, para a realidade brasileira, das noções de "burguês", "burguesia" e "revolução burguesa", procura "estabelecer preliminarmente certas questóes de alcance heurístico" (Idem, 
p. 15). O problema decisivo da obra aparece na discussão da especificidade da construção da sociedade de classes e da revolução burguesa no Brasil, vistas pelo prisma da formação da racionalidade burguesa, da mentalidade burguesa, isto é, de uma ética do "ganho", do "lucro" e do "risco calculado"11. Vale dizer, da gênese da sociedade moderna no Brasil e do desenvolvimento da sociedade de classes, questôes que perpassam a primeira parte dedicada ao estudo do processo da Independência e do desencadeamento da revolução burguesa. Para o tratamento desse período formador, o autor passou em revista o universo valorativo orientador das ações dos agentes envolvidos, apontando para o fato de que a mentalidade econômica, na colônia, “estava sujeita a uma distorção inevitável” (Idem, p. 25). Naturalmente, a análise põe em tela dimensões psicossociais para a caracterização do "espírito burguês".

Por isso, a construção da sociedade nacional, a partir da Independência e do liberalismo, como doutrina de ação das "elites nativas", é crucial, pois se faz possível, daí, vislumbrar a emergência de novos valores orientadores da ação. Em outros termos, o liberalismo produz "formas de poder especificamente políticas e organizadas lucrativamente" e, para uma parte da sociedade, exige a "livre competição" (Idem, p. 48). Emergia, então, "uma área na qual o 'sistema competitivo' pode coexistir e chocar-se com o 'sistema estamental'" (Idem, p. 48). O liberalismo estava na base da emergência e da estruturação da sociedade nacional, mas, ao mesclar-se com componentes da história passada, nem sempre os conseguiu sobrepujar (cf. Idem, p. 39) ${ }^{12}$. Aí, a especificidade da formação histórica brasileira ganha relevo, o que lhe permitiu discutir a problemática da nossa revolução burguesa. Na sua acepção,

[...] trata-se [...] de determinar como se processou a absorção de um padrão estrutural e dinâmico de organização da economia, da sociedade e da cultura. Sem a universalização do trabalho assalariado e a expansão da ordem social competitiva, como iríamos organizar uma economia de mercado de bases monetárias e capitalistas? É dessa perspectiva que o "burguês" e a "revolução" aparecem no horizonte da análise sociológica. Não tivemos todo o passado da Europa, mas reproduzimos de forma peculiar o seu passado recente, pois este era parte do próprio processo de implantação e desenvolvimento da civilização ocidental moderna no Brasil. Falar em revolução burguesa, nesse sentido, consiste em procurar os agentes humanos das grandes transformações histórico-sociais que estão por trás da desagregação do regime escravocrata-senhorial e da formação de uma sociedade de classes no Brasil (Idem, p. 20).
11. O autor se vale das categorias de Sombart (1946, p. 16).

12. Florestan apoia sua análise das dimensões ideológicas e utópicas do liberalismo em Karl Mannheim. 
Centrada na dinâmica social dos agentes, a reflexão procura entender "a formação do chamado 'Brasil moderno', floração cultural da silenciosa revolução socioeconômica, em que aquela revolução política iria desdobrarse, lentamente, ao longo do tempo" (Idem, p. 71). Em suma, a análise procura recuperar a gênese dessa identidade problemática, que está no coração da história brasileira, cuja combinação de elementos díspares responde pela nossa particularidade.

A segunda parte do livro - "A formação da ordem social competitiva" é um fragmento. Como o próprio título alude, o autor dedica-se a entender a formação da ordem social competitiva em países de formação colonial, como o Brasil.

Nas "sociedades nacionais" dependentes, de origem colonial, o capitalismo é introduzido antes da constituição da ordem social competitiva. Ele se defronta com estruturas econômicas, sociais e políticas elaboradas sob o regime colonial, apenas parcial e superficialmente ajustadas aos padrōes capitalistas de vida econômica (Idem, p. 149).

Novamente, Florestan localiza o problema da nossa história na incapacidade ou impossibilidade de superar os princípios inerentes à ordem social anterior. As noçóes de capitalismo dependente e ordem social competitiva estruturam a análise, permitindo-lhe compreender os limites do "estilo competitivo de vida social" e da "mentalidade econômica racional". O problema que se apresenta é detectar o agente social que melhor encarna a condição burguesa de vida. Uma burguesia mercantil urbana, denominada "estamento social intermediário" (Idem, p. 160), expressava os novos valores sociais, mas, apesar disso, não pôde, ou não foi capaz de romper o círculo poderoso advindo do passado.

Aqui, cumpre ressaltar, em especial, a estreita vinculação que se estabeleceu, geneticamente, entre interesses e valores sociais substancialmente conservadores (ou, em outras terminologias: particularistas e elitistas) e a constituição da ordem social competitiva. Por suas raízes históricas, econômicas e políticas, ela atou o presente ao passado como se fosse uma cadeia de ferro. Se a competição concorreu, em um momento histórico, para acelerar a decadência e o colapso da sociedade de castas e estamentos, em outro momento, ela acorrentou a expansão do capitalismo a um privatismo tosco, rigidamente particularista e fundamentalmente autocrático, como se o "burguês moderno" renascesse das cinzas do "senhor antigo" (Idem, pp. 167-168). 
Visto que as atividades comerciais, voltadas ao mercado interno e de cunho capitalista, não foram capazes de se desconectarem da lógica que presidia o movimento do passado, seus agentes assinalaram os mesmos critérios estamentais da ordem escravista, desenhando um estilo de vida semelhante ao da aristocracia agrária (cf. Idem, p. 183). O produto final reflete uma sociedade cujos bloqueios impediram a emergência plena da ordem social competitiva e dos critérios inerentes a uma estrutura de classes, com visíveis e danosas consequências para a construção de "relações sociais superiores" (Idem, 196-197).

Na terceira parte - "Revolução burguesa e capitalismo dependente" - é discutida a gênese da forma de acumulação capitalista dependente e a especificidade de sua realização. Florestan reitera a particularidade da estrutura de classes, do mundo burguês e da burguesia no Brasil. Incapaz de autonomizar-se da oligarquia e de realizar as tarefas típicas da sua congênere europeia, como a criação da nação, e de se tornar o agente fundamental das transformaçôes, a burguesia brasileira vivenciou o dilema histórico da sua situação de classe. Amalgamara-se a forças sociais retrógradas e não implementou a liberal-democracia; o Estado foi a espinha dorsal das mudanças, pois a classe burguesa não deslancha o processo de industrialização. Por tudo isso,

[...] o capitalismo dependente é, por sua própria natureza e em geral, um capitalismo difícil, o qual deixa apenas poucas alternativas efetivas às burguesias que the servem, a um tempo, de parteiras e amas-secas. Desse ângulo, a redução do campo de atuação histórica da burguesia exprime uma realidade específica, a partir da qual a dominação burguesa aparece como conexão histórica não da "revolução nacional e democrática", mas do capitalismo dependente e do tipo de transformação capitalista que ele supõe (Idem, p. 214).

Os impasses da burguesia são as encruzilhadas de uma história dependente dos centros hegemônicos, cujas forças internas não são capazes de romper os liames externos. A ordem capitalista esbarra na ingerência de fora, dados os padrões diversos de desenvolvimento que produzem, por sua vez, uma solidariedade composta por contrários. É por esse motivo que a análise da "revolução burguesa no Brasil consiste na crise do poder burguês, que se localiza na era atual e emerge como consequência da transição do capitalismo competitivo para o capitalismo monopolista” (Idem, p. 215). A partir desse momento, as clivagens manifestam-se com toda a contundên- 
cia. Rupturas que dizem respeito ao andamento da análise e das categorias que a informam. Os dois últimos capítulos - "Natureza e etapas do desenvolvimento capitalista" e "O modelo autocrático-burguês de transformação capitalista” - são elucidativos dessas mudanças.

A envergadura da reflexão desenvolvida no livro, a abrangência do período coberto, o estilo ensaístico da obra e, sobretudo, a consideração do problema da formação histórica da sociedade brasileira permitem filiá-la à tradição dos textos fundamentais de interpretação do Brasil, paradoxalmente completada no momento em que as escolhas de Florestan se afastaram da universidade. É ainda mais significativo revelar o recuo que estabeleceu em relação a suas concepções sobre o ensaio dedicado a tratar da formação histórica da nação brasileira, pois o desconsiderava como expressão legítima da sociologia científica, identificando-o à forma estamental da vida intelectual; do mesmo modo, afirmava a incompatibilidade entre a sociologia científica e os procedimentos da reconstrução histórica, típica dos ensaios (cf. Fernandes, 1963, p. 230; ver, também, 1958, pp. 45-46). O autor não conseguiu preservar o mesmo caráter sistemático de organização das ideias e a mesma crença na inadequação da forma ensaio para o discurso da ciência (cf. Arruda, 2001, p. 315). "Noção a um tempo descritiva e normativa" (Arantes, 1997, p. 12), o princípio da formação e sua recorrência no pensamento brasileiro revelam questôes decisivas de ordem intelectual (cf. Idem, ibidem). Um tipo de avatar do intelectual na periferia do mundo, o primado do ideal de formação permite que se contorne o sentimento de artificialidade de nossa cultura, da ausência de linha evolutiva, da inexistência de "seriação" nas ideias, da persistência da nossa "indiferença”, segundo Sílvio Romero, como resultado do constante domínio da importação intelectual externa sobre a tradição local (Idem, ibidem.).

Com a aceitação da forma ensaio, Florestan Fernandes desviava-se do padrão discursivo que antes afirmava, sem, contudo, afastar-se das análises sociologicamente fundamentadas e rigorosamente perseguidas. Desde sua aposta na constituição da sociedade moderna nos trópicos, passando pela constatação da fragilidade da aclimação desses valores no Brasil, até a confirmação da impossibilidade de se atingir no país o estádio de real civilização, o sociólogo percorreu um trajeto no qual os rumos da história brasileira se mesclaram à sua biografia e à sua sociologia. As edições de Tiago Marques Aibopureu: um Bororo marginal são reveladoras de sua obra e trajetória, pois simbolizam a profundidade da impregnação da sua história de vida pela história brasileira e expõem de forma penetrante como suas circunstâncias 
pessoais confundiram-se com os problemas do Brasil. Nesse contexto, é possível entender as maneiras diferentes como foi refletindo sobre a experiência do país no curso da modernização. Florestan Fernandes reorientou suas apostas, aderindo à política partidária, tentando contornar um dos pilares das suas análises sociológicas que revelavam os efeitos imprevistos e inusitados da ação humana no mundo, distância que, de acordo com sua obra, se aprofundava em sociedades como a brasileira. Possivelmente resida exatamente aí sua principal contribuição para uma nova concepção sobre a formação da sociedade moderna no Brasil.

\section{Referências Bibliográficas}

Arantes, P. E. (1997), "Providências de um crítico literário na periferia do capitalismo”. In: Arantes, O. B. F. \& Arantes, P. E. Sentido da formação: três estudos sobre Antonio Candido, Gilda de Melo e Souza e Lúcio Costa. São Paulo, Paz e Terra.

Araújo, R. B. de. (2005), Guerra e paz: Casa grande \& senzala e a obra de Gilberto Freyre nos anos 30. 2 ed. São Paulo, Editora 34.

Arruda, M. A. do N. (2001), Metrópole e cultura: São Paulo no meio século XX. Bauru, SP, Edusc.

. (2006), "Pensamento brasileiro e sociologia da cultura: questões de interpretação". Clio - Revista do Centro de História da Universidade de Lisboa, 14: 131-141.

Arruda, M. A. do N. \& Garcia, S. G. (2003), Florestan Fernandes: mestre da sociologia moderna. Brasília, Paralelo 15.

Bastos, E. R. (2008), “O outro Brasil de Luís Amaral”. In: Botelho, A.; Bastos, E. R. \& Villas Boas, G. (orgs.). O moderno em questão. A década de 1950 no Brasil. Rio de Janeiro, Topbooks.

Blanco, A. (2006), Razón y modernidad: Gino Germani y la sociologia en la Argentina. Buenos Aires, Siglo XXI.

Botelho, A. (2008), "Uma sociedade em movimento e sua intelligentsia: apresentação". In: Bastos, E. R. \& Villas Boas, G. (orgs.). O moderno em questão: a década de 1950 no Brasil. Rio de Janeiro, Topbooks.

Candido, A. (1996) "Nota final”. In: Lembrando Florestan Fernandes. São Paulo, Edição Particular. - (2000), A educação pela noite e outros ensaios. São Paulo, Ática.

Cardoso, I. (1982), A universidade da comunhão paulista. São Paulo, Cortez.

Entrevista de Florestan Fernandes. (1975), Transformação. Faculdade de Filosofia, Ciências e Letras de Assis (reproduzida posteriormente em Fernandes, F. $A$ condição do sociólogo. São Paulo, Hucitec, 1978). 
Fernandes, F. (s/d.), A organização social dos tupinambá. São Paulo, Progresso. . (1946), "Tiago Marques Aibopureu: um bororo marginal”. Revista do Arquivo Municipal, São Paulo, LVII. . (1958), A etnologia e a sociologia no Brasil. São Paulo, Anhembi. . (1958), O padrão do trabalho científico dos sociólogos brasileiros. Rio de Janeiro, Edição da Revista Brasileira de Estudos Políticos.

- (1960), Mudanças sociais no Brasil. São Paulo, Difusão Europeia do Livro. - (1963), A Sociologia numa era de revolução social. São Paulo, Nacional. - (1965), A integração do negro na sociedade de classes: no limiar de uma nova era. São Paulo, Dominus/Edusp, vol. 2.

. (1970), A Função social da guerra na Sociedade Tupinambá. 2 ed. São Paulo, Pioneira. - (1974), Mudanças sociais no Brasil. 2 ed. São Paulo, Difel. . (1975), A investigação etnológica no Brasil e outros ensaios. Petrópoles, Vozes. . (1975), A revolução burguesa no Brasil: ensaio de interpretação sociológica. Rio de Janeiro, Zahar.

. (1978), A condição de sociólogo. São Paulo, Hucitec. . (1980), A Sociologia no Brasil. 2 ed. Petrópolis, Vozes. . (1995), A contestação necessária: retratos intelectuais de inconformistas e revolucionários. São Paulo, Ática.

Garcia, S. G. (2002), Destino impar: sobre a formação de Florestan Fernandes. São Paulo, Editora 34.

Mannheim, K. (1963), Ensayos de sociología de la cultura: hacia una sociología del espitiru, el problema de la "inteligenstia", la democratización en la cultura. Trad. espanhola. 2. ed. Madri, Aguillar.

Martins, J. de S. (1996), "Vida e história na sociologia de Florestan Fernandes: reflexōes sobre o método da história". Revista USP, 29: 14-19, mar.-maio. . (1998), Florestan: sociologia e consciência social no Brasil. São Paulo, Edusp. Neiburg, F. (1997), Os intelectuais e a invenção do peronismo. São Paulo, Edusp.

SAítTA, S. (2004), "Modos de pensar lo social. Ensayo y la sociedad en la Argentina. 1930-1965”. In: Neiburg, F. \& Plotkin, M. (orgs.). Intelectuales y expertos: la constitución del conocimiento social en la Argentina. Buenos Aires, Paidós.

Simmel, G. (1997), The philosophy of money. Trad. inglesa. Londres, Routledge.

SombarT, Werner. (1946), El apogeo del capitalismo. México, Fondo de Cultura Económica, 2 vols.

Villas BOAS, G. (2006), Mudança provocada: passado e futuro no pensamento sociológico brasileiro. Rio de Janeiro, FGV.

Vianna, L. W. (1997), A revolução passiva: iberismo e americanismo no Brasil. Rio de Janeiro, Revan. 
. (1970), A função social da guerra na sociedade Tupinambá. 2 ed. São Paulo, Pioneira.

. (s/d.), Organização social dos Tupinambá. São Paulo, Progresso.

\section{Resumo}

\section{A sociologia de Florestan Fernandes}

Centrado na obra de Florestan Fernandes, o texto trata das relaçôes entre a constituição da sociologia acadêmica no Brasil, a formação da moderna sociedade capitalista e o movimento modernista. A articulação proposta permite revelar como os caminhos da reflexão sociológica - suas propostas e seus dilemas - podem ser entendidos à luz dos impasses da sociedade moderna brasileira.

Palavras-chave: Sociologia; Florestan Fernandes; Cultura; Sociedade moderna.

\section{Abstract}

\section{The Sociology of Florestan Fernandes}

Focused on the work of Florestan Fernandes, this article deals with the relations between the constitution of academic sociology in Brazil, the formation of modern capitalist society and the modernist movement. The proposed articulation allows us to reveal how the lines of sociological reflection - its proposals and dilemmas - can be understood in the light of the impasses faced by Brazilian society.

Keywords: Sociology; Florestan Fernandes; Culture; Modern society.

Texto recebido em 18/ 2/210 e aprovado em 24/2/2010.

Maria Arminda do Nascimento Arruda é professora Titular da Universidade de São Paulo. Atualmente é Pró-reitora de Cultura e Extensão na mesma universidade. E-mail: <arr@usp.br>. 